\title{
MATERNAL MORTALITY: A PRIORITY ISSUE IN REPRODUCTIVE HEALTH
}

\author{
Imdad A. Khushk and Roshan Ara Qazi
}

Maternal mortality is best defined as death of women during pregnancy or within 42 days of termination of pregnancy from a cause related to or aggravated by pregnancy or its management but not from accidental or incidental cause. Pregnancy is not a disease and pregnancy related morbidity and mortality are preventable. Despite that, more than half a million maternal deaths are reported worldwide each year, with vast majority of these deaths occurring in developing countries. $^{1}$

In Western hemisphere of world, maternal mortality ratio (MMR) remained disturbingly high form late nineteenth century till the mid 1930's and then began to fall rapidly. A comparison of MMRs between 1870 and 1950 in certain European countries, especially Great Britain, Australia, New Zealand and the USA, suggests that between 1870 and 1935, it was usually considered safe to be delivered at home by a welltrained midwife rather than by a doctor in a hospital but it was no safer to be rich rather than poor. ${ }^{2}$ Canadian regional MMRs were also persistently high until 1939, then showed a declining trend. ${ }^{3}$ Advances in obstetrics have contributed in declining these trends but compositional influences were also important. Favourable changes in mother's age-parity distributions contributed upto 24\% drop in MMRs between 19391960 and 1965-1969. Due to their continued efforts, now MMR from developed world is reported from zero to a maximum of $13 / 100,000$ live births (LB). ${ }^{4}$ In developed countries, MMR is now a forgotten chapter in the medical history mainly due to their high socioeconomic conditions, better education and advanced obstetric care. While in developing countries, situation in this regard is vice versa.

Research reports reveal that majority of maternal deaths are preventable and maternal health depends strongly upon quality of health care, and maternal mortality acts as a litmus test of women, of their access to health care and response of health care to their needs. South Asian developing countries Pakistan, India and Bangladesh have major share in maternal deaths worldwide. These countries account for about $28 \%$ of total births and $46 \%$ of maternal deaths in the world. Latest available data from India and Bangladesh show that MMRs in these countries have significantly declined during last few years. ${ }^{5-7}$ In rural India, MMR upto 260/100,000 LB has been reported. ${ }^{6}$ Meanwhile in Bangladesh, national direct obstetric death rate has reached 16.9/100,000 women, where decline in fertility have led to estimated $49 \%$ reduction in MMR per 1000 women during past 18 years. $^{7}$

Pakistan still has a poor situation regarding maternal health ${ }^{8}$ and trends in MMR continue to grow despite serious efforts to reduce such deaths. For the years 2001-2002, MMR was reported as 327-1300/100,000 LB. ${ }^{9}$ On average, estimated 500 maternal deaths/ 100,000 LB are occurring each year in this country. ${ }^{10}$ This figure is highest in world following some African countries. ${ }^{11}$ Pakistani estimates regarding MMR are mostly based on hospital statistics. In fact, majority of women, mostly from rural areas, do not receive antenatal care and majority of the deliveries take place at home which are attended by untrained personnel. About $90 \%$ of these deaths occur in peak reproductive age group (i.e. 15-35 years). So the actual figures of MMR would be more than reported. The causes of maternal mortality are multiple, inter-related, complex and almost always preventable. Obstetric hemorrhages, eclampsia and puerperal sepsis are commonly reported direct causes of MMR in Pakistan as well as in other parts of the globe. ${ }^{12-14}$ Meanwhile, indirect causes include anaemia, cardiomyopathy, pulmonary embolism, diabetic ketoacidosis, anaesthesia, corpulmonale, infectious diseases and malignancies. Most of these medical problems are either preventable or treatable if managed in time. A combination of economic, social and cultural factors also plays a significant role in maternal deaths. In this country, teenage marriages are common and high fertility rates, high levels of poverty and illiteracy as well as gender discrimination also prevail which compound the situation. In fact, a poor woman is many times more likely to die during childbirth due to malnutrition and anaemia.

Hence, Pakistan is facing unacceptable state of maternal health, so policy change with more comprehensive and integrated approaches to maternal health services is the need of hour. ${ }^{15}$ In this regard, strategies need to be developed which are short term, medium term and long term. This includes competency based training, deployment and supervision of a cadre of skilled birth attendants at the community level. In addition, upgrading of existing health care systems especially availability of cost effective emergency obstetric care including essential laboratory and blood bank services with the adoption of fast referral system particularly in the far-flung rural areas is urgently 
required. There is also need of better community participation and establishing linkages with non governmental organizations to enhance reproductive health programs. These efforts combined with measures aimed at reducing fertility rates, and poverty coupled with improvement in the socioeconomic and educational status especially for women can definitely help in reduction of maternal mortality. Mass media campaigns regarding maternal health and antenatal checking during pregnancies would also be worthwhile. There is also need to strengthen information systems throughout the country for evidence based decision-making, planning and evaluation of maternal health programs. Finally, effective public-private partnership is must for improvement in maternal health in Pakistan.

\section{REFERENCES}

1. AbouZahr C, Wardlaw T. Maternal mortality in 2000: estimates developed by WHO, UNICEF and UNFPA. Geneva: World Health Organizaton, 2004.

2. Loudon I. Maternal mortality: 1880-1950. Some regional and international comparisons. Soc Hist Med. 1998; 1: 183-228.

3. Emery G. Age-parity and marital status compositional influences on maternal mortality rates in Canada, 1930-1969: A regional comparison. Soc His Med. 1992; 25: 229-56.

4. Bouvier-Colle MH, Pequignot F, Jouglae. Maternal mortality in France: frequency, trends and causes. J Gynecol Obstet Biol Reprod (Paris) 2001; 30: 768-75.

5. Baul MK, Manjusha. Maternal mortality--a ten-year study. J Indian Med Assoc. 2004;102 (1):18-9, 25.

6. Chhabra S, Sirohi R. Averting maternal deaths in spite of resource constraints: an Indian rural experience over two decades. J Obstet Gynaecol. 2004;24(5):521-4.

7. Rehman $\mathrm{MH}$, Akhtar $\mathrm{MH}$, Khan Chowdhury ME, Yusuf HR, Rochat RW. Obstetric deaths in Bangladesh, 1996-1997. Int J Gynecol Obstet. 2002; 77: 161-9.

8. Siddiqi S, Haq IU, Ghaffar A, Akhtar T, Mahaini R. Pakistan's maternal and child health policy: analysis, lessons and the way forward. Health Policy. 2004;69(1):117-30.

9. Khushk IA, Baig LA. Maternal mortality in Pakistan: no room for complacency! J Coll Physicians Surg Pak. 2002; 12: 511-2.

10. Farooq $\mathrm{N}$, Jadoon $\mathrm{H}$, Masood TI, Wazir MS, Farooq U, Lodhi MS. An assessment study of maternal mortality ratio databank in five districts of North Western Frontier Province Pakistan. J Ayub Med Coll Abbottabad. 2006;18(2):64-8.

11. Ujah IA, Aisien OA, Mutihir JT, Vanderjagt DJ, Glew RH, Uguru VE. Factors contributing to maternal mortality in north-central Nigeria: a seventeen-year review. Afr J Reprod Health. 2005; 9:27-40.

12. Akbar N, Shami N, Asif S. Maternal mortality in a tertiary care teaching hospital. J Coll Physicians Surg Pak. 2002; 12: 429-431.

13. Fikree FF, Gray RH, Berendes HW, Karim MS. A community-based nested case-control study of maternal mortality. Int J Gynaecol Obstet. 1994;47: 247-55.

14. Begum S, Aziz-u-Nisa, Begum I. Analysis of maternal mortality in a tertiary care hospital to determine causes and preventable factors. J Ayub Med Coll Abbottabad. 2003; 15 (2):49-52.

15. Jafarey SN. Maternal mortality in Pakistan - compilation of available data. J Pak Med Assoc. 2002; 52(12):539-44.

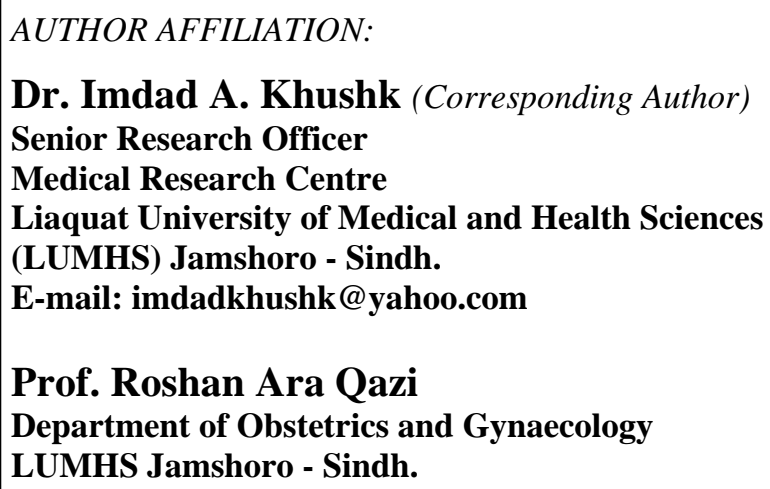

